\title{
Biology of Cabbage Butterfly Pieris brassicae Linn. (Lepidoptera: Pieridae)
}

\author{
Madhumita Bhowmik* and M.K. Gupta \\ Department of Entomology, College of Agriculture, Central Agricultural University, \\ Imphal, Manipur-795004, India \\ *Corresponding author
}

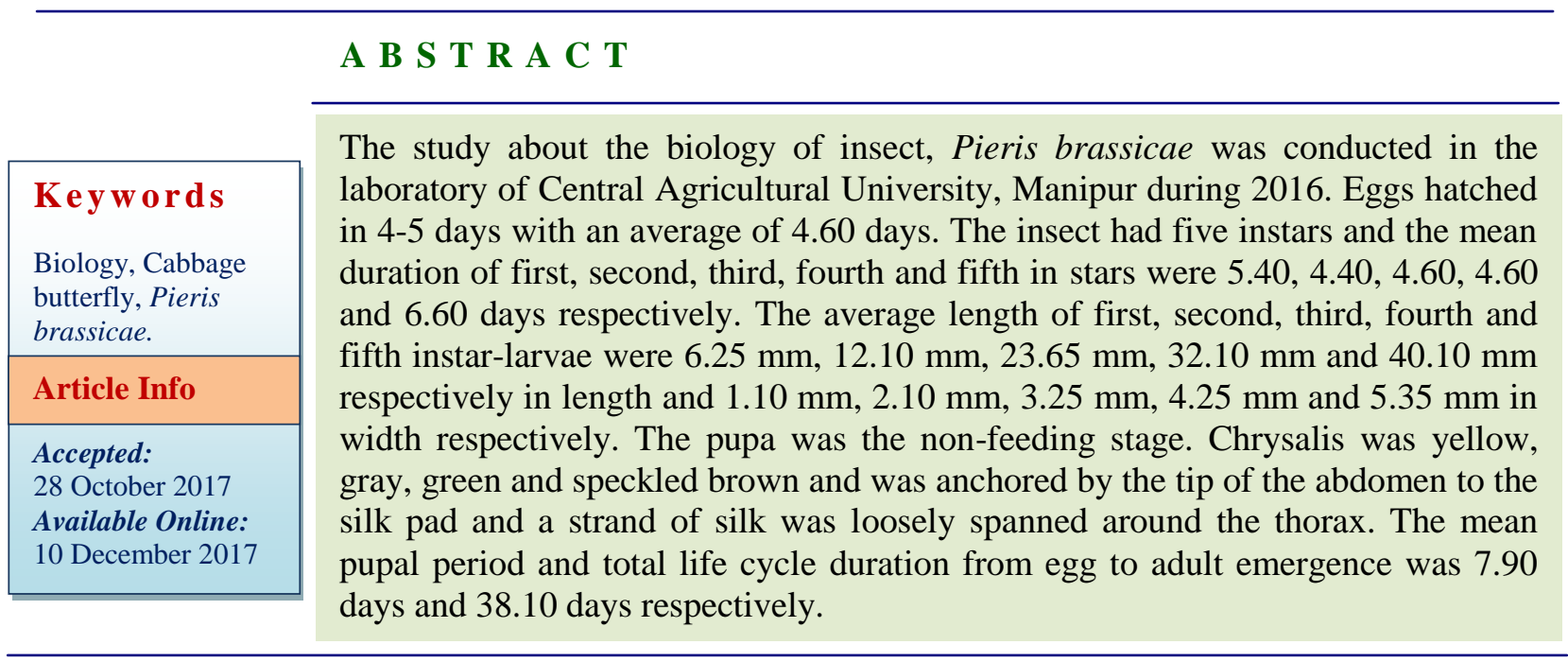

\section{Introduction}

Cabbage is scientifically known as Brassicae oleracea var. capitata. It belongs to brassicaceae family. It is one of the important cole crops grown mostly in winter season which occupy an important position in meeting dietary requirement of most of the people all over the world. The productivity of cabbage in India is $22.9 \mathrm{MT} / \mathrm{ha}$ which is less than that the world which is $29.4 \mathrm{MT} / \mathrm{ha}$ (Anonymous, 2013). In Manipur the productivity is only $12.87 \mathrm{MT} / \mathrm{ha}$ (Anonymous, 2011). The reason for this low yield can be attributed to several abiotic and biotic factors, among them the insect pest is considered as one of the major constraints. In India, a total of 37 insect pests have been reported to feed on cabbage (Lal, 1975). Vegetable crops like cabbage, cauliflower, broccoli, Brussels sprouts, collards, mustard, radish, turnip and watercress attacked by cabbage butterfly. Their eggs are ribbed vertically and laid upright in clusters of 40100 which changes from white or pale yellow to bright orange color before hatching. Large white larvae experience four moultings and five instars. Among the different instars, the third instar larvae are observed to eat voraciously and cause significant amounts of damage to their host plant. They are observed to be more yellow in color, studded with black dots. Pupa is pale green or greyishwhite and dotted with black and yellow 
markings. Adult butterfly, for both males and females, have white wings with black tips on the forewings. The female also has two black spots on each forewing. The Large white butterfly wingspan reaches 5 to $6.5 \mathrm{~cm}$ on average. This study aims to identify different stages of cabbage butterfly, Pieris braasicae; based on which effective control measures can be initiated.

\section{Materials and Methods}

The experiment was set up in Completely Randomized Design with three replication. Larvae of Pieris brassicae were collected from cabbage field and reared on cabbage leaves in glass petriplates $(21 \mathrm{~cm}$ dia) in the laboratory for pupation and adult emergence. The moth emerged were released in rearing cages containing 4-5 leaf stage of cabbage plants grown in disposable plastic cups for oviposition. The plants containing the egg masses of $P$. brassicae were kept in petriplate over a moist filter paper for hatching. On hatching, 10 neonate larvae were transferred singly to cabbage leaf pieces kept in petriplate over a moist filter paper for feeding. The larvae were supplied with fresh leaves daily till pupation. Observations were taken on incubation period based on eggs. At each moult, the head capsules were separated out and their size were measured. Size of larva for each instar and pupa was also measured. Duration of larval instars and pupa were recorded. Adult male and female sizes and their duration were recorded. All the observations were based on 10 individuals.

\section{Results and Discussion}

\section{Egg}

The female butterfly laid eggs in masses. The biggest egg mass consisted of 116 eggs. However, some egg mass consists of 2-3 eggs only. The freshly laid eggs were yellowish but gradually turned to dark yellow and finally greyish at the time of hatching. The eggs were sculptured like that of maize cob. Eggs were glued to the leaf surface by brownish secretions made by the female. The eggs hatched in 4-5 days with an average of 4.60 days (Table 1). The eggs measured 1.25 to $1.30 \mathrm{~mm}$ with an average of $1.28 \mathrm{~mm}$ (Table 3) in length and 0.48 to $0.50 \mathrm{~mm}$ in width with an average of $0.49 \mathrm{~mm}$.

\section{Larva}

The larva underwent four moulting and five instars. The first instar larvae on hatching were light yellow in colour with distinct shiny black heads. The first instar larvae measured 6.0 to $6.5 \mathrm{~mm}$ in length with an average of $6.25 \mathrm{~mm}$ and 1.0 to $1.2 \mathrm{~mm}$ in width with an average of $1.10 \mathrm{~mm}$ (Table 3 ). The head capsule of first instar larvae measured 0.8 to $0.9 \mathrm{~mm}$ with an average of $0.85 \mathrm{~mm}$ (Table 4). The duration of first instar varied from 4.0 to 6.0 days with an average of 5.40 days (Table 1). The second instar larvae were greenish yellow in colour with black head and body was covered with short hairs. The second instar measured 12.0 to $12.2 \mathrm{~mm}$ with an average of $12.1 \mathrm{~mm}$ in length and 2.0 to $2.2 \mathrm{~mm}$ with an average of $2.1 \mathrm{~mm}$ in width (Table 3). The head capsule of second instar larvae measured 1.75 to $1.8 \mathrm{~mm}$ with an average of $1.77 \mathrm{~mm}$ (Table 4). The duration of the second instar varied from 4.0 to 5.0 days with an average of 4.40 days (Table 1). The third instar was greenish in colour with black heads. The body was covered with black hairs on raised tubercles. There were five longitudinal yellowish lines one dorsally and two laterally on each side. The third instar measured 23.6 to $23.7 \mathrm{~mm}$ with an average of $23.65 \mathrm{~mm}$ in length and 3.0 to $3.5 \mathrm{~mm}$ with an average of $3.25 \mathrm{~mm}$ in width (Table 3 ). The duration of the third instar varied from 4.0 to 5.0 days with an average of 4.60 days (Table 1). The head capsule of third instar measured 
2.5 to $2.6 \mathrm{~mm}$ with an average of $2.55 \mathrm{~mm}$ (Table 4). The fourth instar larvae were similar to those of third instar larvae in appearance. The fourth instar measured 32.0 to $32.2 \mathrm{~mm}$ in length with an average of 32.1 $\mathrm{mm}$ and the width varied from 4.2 to $4.3 \mathrm{~mm}$ with an average of $4.25 \mathrm{~mm}$ (Table 3). The duration of the fourth instar was 4.0 to 5.0 days with an average of 4.6 days (Table 1).

The head capsule of fourth instar measured 3.25 to $3.49 \mathrm{~mm}$ with an average of $3.37 \mathrm{~mm}$ (Table 4). The fifth instar larvae were cylindrical, robust and elongated, yellow in colour with bright colouration on their abdomen and thorax. The head was black. The longitudinal lines on the body were similar to the fourth instar. Body was covered with black hairs on raised tubercles. The fifth instar measured 40.0 to $40.2 \mathrm{~mm}$ with an average of $40.1 \mathrm{~mm}$ in length and the width varied from 5.2 to $5.5 \mathrm{~mm}$ with an average of $5.35 \mathrm{~mm}$ (Table 3). The duration of fifth instar larvae was 6.0 to 7.0 days with an average of 6.6 days (Table 1). The head capsule of fifth instar larvae measured 4 to 4.2 $\mathrm{mm}$ with an average of $4.1 \mathrm{~mm}$ (Table 4). All the larval instars had five pairs of prolegs. The total larval duration varied from 22 to 28 days with an average of 25.6 days.

\section{Pupa}

Pupa was pale green or greyish white and dotted with black and yellow markings. The ventral surface was flattened. There was a lateral ridge along either side and a similar ridge extends from the forward-printing head up over head, thorax and abdomen. Several blunt spikes were also found on the abdomen. The size of pupa varied from 20.0 to $25.0 \mathrm{~mm}$ in length with an average of $22.5 \mathrm{~mm}$ and width varied from 3.0 to $3.2 \mathrm{~mm}$ with an average of $3.1 \mathrm{~mm}$ (Table 3). The pupal duration ranged from 7.0 to 9.0 days with an average of 7.9 days (Table 1 ).

Table.1 Duration of egg, larva, pupa and total life cycle of $P$. brassicae

\begin{tabular}{|c|c|c|}
\hline Parameters & Mean duration (in days \pm s.d) & Range \\
\hline Incubation period & $4.60 \pm 0.55$ & $4-5$ \\
\hline Larval period Instar 1 & $5.40 \pm 0.92$ & $4-6$ \\
\hline Instar ll & $4.40 \pm 0.52$ & $4-5$ \\
\hline Instar lll & $4.60 \pm 0.52$ & $4-5$ \\
\hline Instar IV & $4.60 \pm 0.52$ & $4-5$ \\
\hline Instar V & $6.60 \pm 0.52$ & $6-7$ \\
\hline Pupal period & $7.90 \pm 0.74$ & $7-9$ \\
\hline $\begin{array}{c}\text { Total life cycle(Egg to adult } \\
\text { emergence) }\end{array}$ & $38.10 \pm 2.32$ & $32-39$ \\
\hline
\end{tabular}

Data based on 10 individuals.

Table.2 Longevity of adult $P$. brassicae

\begin{tabular}{|l|c|c|}
\hline \multicolumn{1}{|c|}{ Parameters } & Mean longevity(days) \pm s.d & Range \\
\hline Adult longevity(Male) & $6.80 \pm 0.79$ & $6-8$ \\
\hline Adult longevity(Female) & $6.50 \pm 0.53$ & $6-7$ \\
\hline
\end{tabular}

Data based on 10 individuals. 
Table.3 Size of egg, larva, pupa of $P$. brassicae

\begin{tabular}{|c|c|c|c|c|}
\hline Parameters & Length & Range & Width & Range \\
\hline Egg & $1.28 \pm 0.03$ & $1.25-1.3$ & $0.49 \pm 0.01$ & $0.48-0.5$ \\
\hline Larva Instar 1 & $6.25 \pm 0.26$ & $6-6.5$ & $1.10 \pm 0.1$ & $1-1.2$ \\
\hline Instar ll & $12.10 \pm 0.1$ & $12-12.2$ & $2.10 \pm 0.1$ & $2-2.2$ \\
\hline Instar 1ll & $23.65 \pm 0.05$ & $23.6-23.7$ & $3.25 \pm 0.26$ & $3-3.5$ \\
\hline Instar lV & $32.10 \pm 0.1$ & $32-32.2$ & $4.25 \pm 0.05$ & $4.2-4.3$ \\
\hline Instar V & $40.10 \pm 0.1$ & $40-40.2$ & $5.35 \pm 0.17$ & $5.2-5.5$ \\
\hline Pupa & $22.50 \pm 2.63$ & $20-25$ & $3.10 \pm 0.1$ & $3-3.2$ \\
\hline
\end{tabular}

Data based on 10 individuals.

Table.4 Size of head capsule of $P$. brassicae

\begin{tabular}{|c|c|c|}
\hline Parameters & Size(in $\mathbf{~ m m} \pm \mathbf{s . d})$ & Range \\
\hline Head capsule of instar 1 & $0.85 \pm 0.05$ & $0.8-0.9$ \\
\hline Instar ll & $1.77 \pm 0.03$ & $1.75-1.8$ \\
\hline Instar lll & $2.55 \pm 0.05$ & $2.5-2.6$ \\
\hline Instar 1V & $3.37 \pm 0.1$ & $3.25-3.49$ \\
\hline Instar V & $4.10 \pm 0.1$ & $4-4.2$ \\
\hline
\end{tabular}

Data based on 10 individuals.

Table.5 Size of wingspan of adult $P$. brassicae

\begin{tabular}{|c|c|c|}
\hline Parameters & Length(in cm \pm s.d) & Range \\
\hline Adult wingspan(Male) & $5.10 \pm 0.1$ & $5-5.2$ \\
\hline Adult wingspan(Female) & $5.50 \pm 0.2$ & $5-6$ \\
\hline
\end{tabular}

Data based on 10 individuals.

\section{Adult}

The butterflies were pale white and had a smoky shade on the dorsal side of the body. The wings are white with black tips on the forewings in case of both males and females which was augmented in the females (which had a larger black tip) by a pair of post-diseal black spots with a black smear along the inner margin below the lower spot. The undersides of both sets of wings were pale yellow, dusted with grey except for the centre and base of the forewings which were white. In female, the black dots of the forewings also appeared on the undersides. The head, thorax and abdomen were black with grey hair-like scales. The longevity of male butterfly was
6.0 to 8.0 days with an average of 6.8 days while the longevity of female was 6.0 to 7.0 days with an average of 6.5 days (Table 2). The wing expanse of male butterfly was 5 to $5.2 \mathrm{~cm}$ with an average of $5.1 \mathrm{~cm}$ and the wing expanse of female was 5 to $6 \mathrm{~cm}$ with an average of $5.5 \mathrm{~cm}$ (Table 5).

\section{Statistical analysis}

The percentage data of the experiment were transformed (wherever necessary) by using suitable transformation in order to make the analysis of variance valid and feasible. The data thus transformed were statistically analysed with the help of analysis of variance technique. When ' $F$ ' values found significant, 
than treatment means were compared by using C.D. (critical difference) values at 5\% level of probability. The C.D. value were obtained by multiplying the standard error of mean difference with table value of $\mathrm{t}$ at $5 \%$ or $1 \%$ level of probability for error degree of freedom (d.f). Means were separated by LSD test.

The female butterfly laid eggs in masses glued to leaf surface by brownish secretion made by the females. The egg hatched in 4-5 days with an average of 4.60 days (Table 1). The egg measured $1.28 \pm 0.03 \mathrm{~mm}$ in length and $0.49 \pm 0.01 \mathrm{~mm}$ in width. Soud and Bhalla (1996), Chandel et al., (1998) and Thapa (1987) reported incubation period of 7.0 days, 4.75- 11.90 days and 3.1 days respectively which is in conformity with the present finding. The insect had five instars and the first instar larvae on hatching were light yellow in colour with shiny black heads. The insect had five instars and the first instar larvae on hatching were light yellow in colour with shiny black heads. The mean length of first, second, third, fourth and fifth instar larvae were $6.25 \mathrm{~mm}, 12.1 \mathrm{~mm}, 23.65 \mathrm{~mm}$, $32.1 \mathrm{~mm}$ and $40.1 \mathrm{~mm}$ respectively in length and $1.1 \mathrm{~mm}, 2.1 \mathrm{~mm}, 3.25 \mathrm{~mm}, 4.25 \mathrm{~mm}$ and $5.35 \mathrm{~mm}$ in width respectively (Table 3 ). The pupa was the non-feeding stage. Chrysalis was yellow, gray, green and speckled brown and was anchored by the tip of the abdomen to the silk pad and a strand of silk was loosely spunned around the thorax.

The average length and width of pupa were $22.5 \mathrm{~mm}$ and $3.1 \mathrm{~mm}$ respectively (Table 3 ). The average size of headcapsule of first, second, third, fourth and fifth instar were 0.85 $\mathrm{mm}, 1.77 \mathrm{~mm}, 2.55 \mathrm{~mm}, 3.37 \mathrm{~mm}$ and 4.10 $\mathrm{mm}$ respectively (Table 4 ). The mean duration of first, second, third, fourth and fifth instar were 5.40 days, 4.40 days, 4.60 days, 4.60 days and 6.60 days respectively (Table 1). The mean pupal period and total life cycle duration from egg to adult emergence was 7.90 days and 38.10 days respectively (Table 1). Bhubaneswari et al., (2012) also reported the morphometric measurements of $P$. brassicae and the mean length of first, second, third, fourth and fifth instar larvae were $4.4 \mathrm{~mm}, 12.3 \mathrm{~mm}, 15.9 \mathrm{~mm}, 27.6 \mathrm{~mm}$ and $39.74 \mathrm{~mm}$ respectively and the mean width were $0.76 \mathrm{~mm}, 1.24 \mathrm{~mm}, 1.70 \mathrm{~mm}$, $2.74 \mathrm{~mm}$ and $4.12 \mathrm{~mm}$ respectively which almost similar to those obtained in the present investigation. The pupal length $(24.36 \mathrm{~mm})$ and width $(8.42 \mathrm{~mm})$ obtained by Bhubaneswari et al., (2012) was also similar to those obtained in the present investigation. In present investigation, the mean larval duration of first, second, third, fourth and fifth instar larva was 5.40 days, 4.40 days, 4.60 days, 4.60 days and 6.60 days respectively which was similar to those obtained by Chahil and Kular (2013), Gupta (1984), Chandel et al., (1998) and Soud and Bhalla (1996). Similarly the total developmental period obtained in the present finding was similar to those obtained by Chahil and Kular (2013) which was 42 days when the insect was reared on Brassica carinata.

Investigation on the biology of $P$. brassicae were conducted in the laboratory, Department of Entomology, Central Agricultural University, Imphal. Duration of incubation period was $4.60 \pm 0.55$ days. Duration of first, second, third, fourth and fifth instar larva was 5.40, 4.4, 4.6, 4.6, 6.6 days respectively. Duration of pupa was 7.9 day.

Adult longevity for male was 6.8 days while for female, it was 6.5 days. Length of egg was $1.28 \mathrm{~mm}$, width was $0.49 \mathrm{~mm}$. Length of different instars were $6.25 \mathrm{~mm}, 12.1 \mathrm{~mm}$, $23.65 \mathrm{~mm}, 32.1 \mathrm{~mm}$ and $40.1 \mathrm{~mm}$ (from instar 1 to $\mathrm{V}$ ) and width was $1.1 \mathrm{~mm}, 2.1 \mathrm{~mm}$, $3.25 \mathrm{~mm}, 4.25 \mathrm{~mm}$ and $5.35 \mathrm{~mm}$. Length of pupa was $22.5 \mathrm{~mm}$ and width was $3.1 \mathrm{~mm}$. Adult wingspan was $5.1 \mathrm{~cm}$. 


\section{Acknowledgement}

The authors are thankful to the Dean of Central Agricultural University, Imphal for providing laboratory facilities and also thankful to the workers of Department of Entomology for their support to conduct the experiment.

\section{References}

Anonymous, (2011) Indian Horticulture Database (2011) Crop Statistics. Http://ihb.gov.in/doc-1/database. 2011. pdf.

Anonymous, (2013). Indian Horticulture Database (2013) Crop Statistics. Http://ihb.gov.in/doc-1/database. 2013. pdf.

Bhubaneshawari, M., Kananbala, A., Joymati, L., Ronikumar, L. and Binarani, A. (2012). Morphometric Measurement of Cabbage Butterfly Pieris brassicae (L.) (Lepidoptera: Pieridae) in the Agro Ecosystem of Manipur. International
Journal of Basic and Applied Medical Sciences, 2: 31-33.

Chahil, G. S. and Kular, J. S. (2013). Biology of Pieris brassicae on Different Brassica Species in the plain of Punjab. J. Pl. Protec. Res., 53: 53-59.

Chandel, R. S., Kashyap, N. P. and Mehta, P. K. (1998). Biology of Pieris brassicae (Linn.) in dry temperate zone of Himachal Pradesh. J. Insect Sci. 11(1): 71-73.

Gupta, P. R. (1984). Bionomics of the cabbage butterfly Pieris brassicae (L.) in the mid- hills of Himachal Pradesh. $J$. Agric. Res. 10(1):49-54.

Lal, O. P. (1975). A compendium of insect pests of vegetables in India. Bull. Entomol., 16: 51-56.

Sood, A. K. and Bhalla, O.P. (1996). Ecological studies on the cabbage white butterfly in the mid- hills of Himachal Pradesh. J. Insect Sci., 9(2): 122-125.

Thapa, R. B. (1987). Biology of Pieris brassicae in Chitwan Valley. Pesticides. 21(1): 30- 33 .

\section{How to cite this article:}

Madhumita Bhowmik and Gupta, M.K. 2017. Biology of Cabbage Butterfly Pieris brassicae Linn. (Lepidoptera: Pieridae). Int.J.Curr.Microbiol.App.Sci. 6(12): 3639-3644.

doi: https://doi.org/10.20546/ijcmas.2017.612.420 